\title{
LIQUID NITROGEN SUBCOOLER FOR CALORIMETERS LN2 SUPPLY. PRESSURE VESSEL CALCULATIONS
}

\author{
ENGINEERING NOTE
}

3823.115-EN-570

February 16, 2004

Author: Mike Sarychev 


\section{PRESSURE VESSEL ENGINERING NOTE}

\section{PER CHAPTER 5031}

Prepared by: Mike SarycheV Preparation date: 12.11 .02

1. Description and Identification Fill in the label information below:

This vessel conforms to Fermilab ES\&H Manual Chapter 5031

vessel title $\angle N_{2}$ fulcooLeg

vessel Number PDD 70075

$\leftarrow$ Obtain from Division/Section Safety Officer

vessel Drawing Number $3823.124-M E-399599$

Maximum Allowable Working Pressures (MAWP) :

Internal Pressure

External Pressure 20 psis

Working Temperature Range $-320{ }^{\circ}, 300{ }^{\circ} \mathrm{F}$ Contents LIQUID NITROGEN Designer/Manufacturer DPWAR-MINAESOTA VALLEY ENG:NERING: DOP - FERMICAB Test Pressure (if tested at Fermi) Acceptance Date: $120 / 04$

$\leftarrow$ Document per Chapter 5034 of the Fermilab ES\&H Manual

22 Psig, Hydraulic. Accepted as conforming to stapdard by

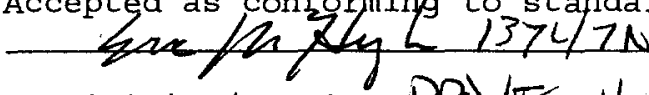

of Division/section PP/FS*H

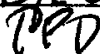

neumatis
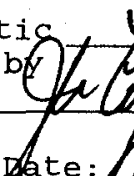
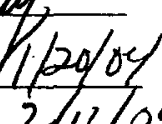

« Actual signature required

NOTE: Any subsequent changes in contents,

pressures, temperatures, valving, etc., which

affect the safety of this vessel shall require

another review. EdWard CHI

Reviewed by:

pPd/MD/ME. Date

$32 \cos \cdot 28,2004$

Director's signature (or designee) if the vessel is for manned areas but doesn't conform to the requirements of the chapter.

Date: 
Lab Property Number (s):

Lab Location Code:

Purpose of Vessel (s):

$$
\text { LIQUID NITROGEN }
$$

Vessel Capacity/size: 25.5 eite

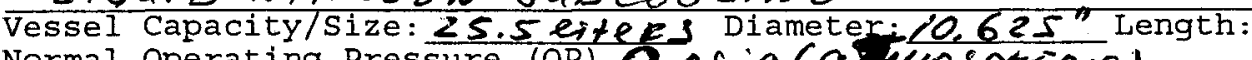

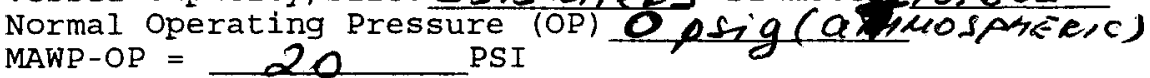

$N / A$ PPS -325 (DAB) (obtain from safety officer) List the numbers of all pertinent drawings and the location of the originals. Drawing \# $3823.124-M E-399599$ Location of original DPASSEMSCY building, High BAY

2. Design Verification

Is this vessel designed and built to meet the Code or "In-House Built" requirements?

Yes $X$ No

If "No" state the standard that was used

N/A

Demonstrate that design calculations of that standard have been made and that other requirements of that standard have been satisfied.

skip to part 3 "system venting verification" BO

Does the vessel(s) have a U stamp? Yes $X$ No $X$. If "Yes", complete section $2 \mathrm{~A}$; if "No", complete section $\overline{2 B}$.

A. Staple photo of $U$ stamp plate below. Copy "U" label details to the side

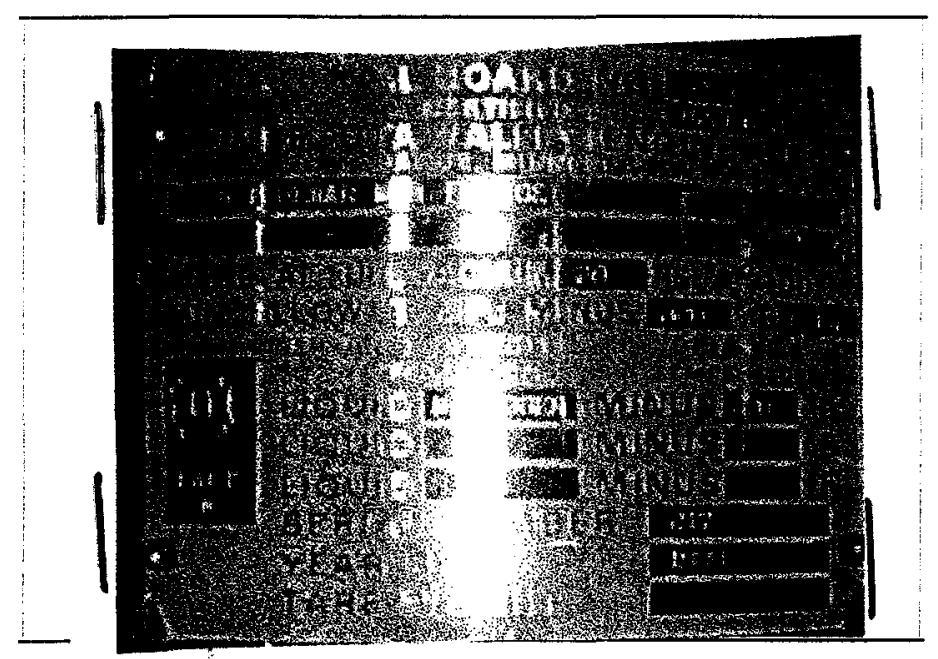

Copy data here:

NAT'L Boaed No 20939 himne to ta Vapley Engsureesirc H-I DewAR W/B- FLANGE MAWP at Full VACUUM 20 psi at 100\% Min. Allow Temp:- $320^{\circ} \mathrm{K}$ device: $2 N_{2}$ at $-320 \%$ Serial No $2 / 7$ Year BuilT/1988 
Provide ASME design calculations in an appendix. On the sketch below, circle all applicable sections of the ASME code per Section VIII, Division I. (Only for non-coded vessels)

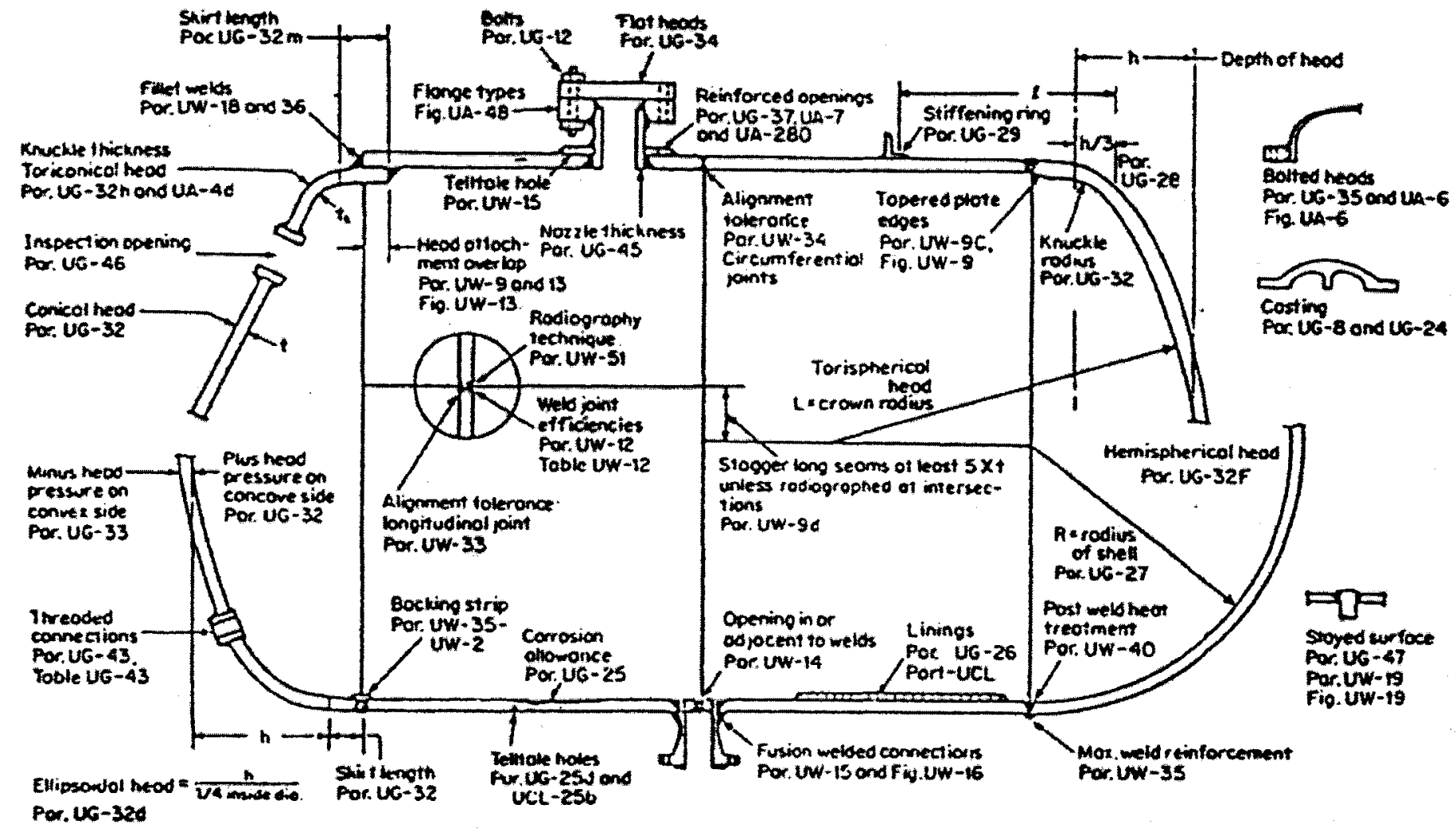

Figure 1. ASME Code: Applicable Sections

2B.

Summary of ASME Code

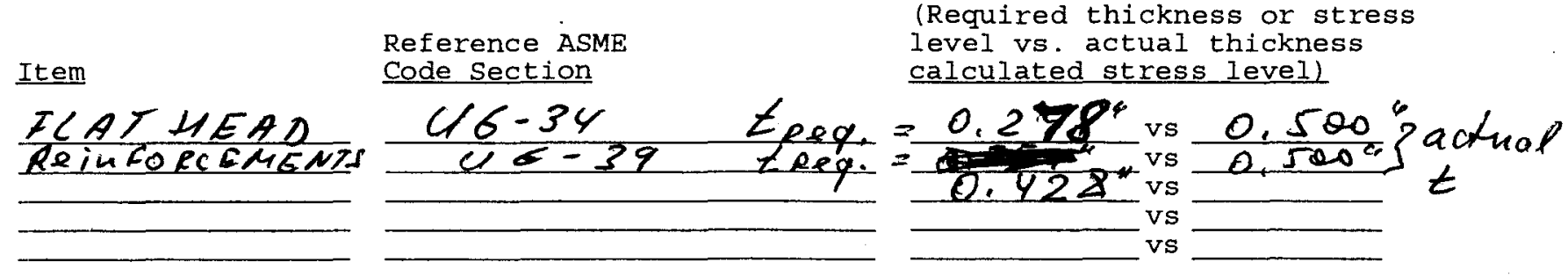


3. System Venting Verification Provide the vent system schematic.

Does the venting system follow the Code UG-125 through UG-137? Yes $X$ No

Does the venting system also follow the Compressed Gas Association Standards $\mathrm{S}-1.1$ and $\mathrm{S}-1.3$ ?

Yes $X$ No

A "no" response to both of the two proceeding questions requires a justification and statement regarding what standards were applied to verify system venting is adequate.

List of reliefs and settings:

Manufacturer $\quad$ Model \# Set Pressure Flow Rate size

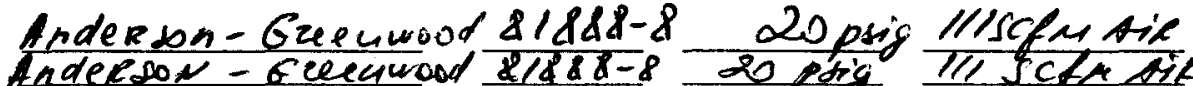

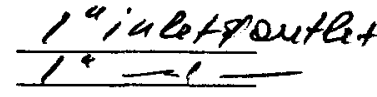

4. Operating Procedure

Is an operating procedure necessary for the safe operation of this vessel? Yes No $X$ (If "Yes", it must be appended)

5. Welding Information $70 P-D Q A R$

Has the vessel been fabricated in a non-code shop? Yes $X$ No $\chi$ If "Yes", append a copy of the welding shop statement of welder qualification (Procedure Qualification Record, PQR) which references the Welding Procedure Specification (WPS) used to weld this vessel.

6. Existing, Used and Unmanned Area Vessels

Is this vessel or any part thereof in the above categories?

Yes X No

If "Yes", follow the requirements for an Extended Engineering Note for Existing, Used and Unmanned Area Vessels.

7. Exceptional Vessels

Is this vessel or any part thereof in the above category? Yes No $X$

If "Yes", follow the requirements for an Extended Engineering Note for Exceptional Vessels.

* The Minnesota volley $U$-stamper decrar was used on Argon purity test - vessec RD-1102 
Pressure relief calculations

\section{Summary}

\begin{tabular}{|c|c|c|}
\hline Case & $\begin{array}{c}\text { Req'd Flow Rate } \\
\text { scfm air }\end{array}$ & $\begin{array}{c}\text { Actual Flow Rate } \\
\text { scfm air }\end{array}$ \\
\hline $\begin{array}{c}\text { Emergency Conditions } \\
\text { (loss of vacuum) }\end{array}$ & 1.47 & 111 \\
\hline Fire & 5.24 & 111 \\
\hline Maximum Fill Rate & 21.3 & 111 \\
\hline
\end{tabular}


Fermilab

EXHIBIT B

Pressure Testing Permit*

Date: $01 / 05 / 04$

Type of Test []Hydrostatic [ $]$ Pneumatic

Test Pressure $\quad 22$ prig Maximum Allowable Working Pressure $\quad 20 \quad$ psi

Items to be Tested

LN 2 Lubcoolere asfecublg DD 100>5

Location of Test

Hazards Involved $\triangle A B$

Date and Time

None

Safety Precautions Taken

Fences will be installed to prevent in-autho rived access.

Special Conditions or Requirements

no ne

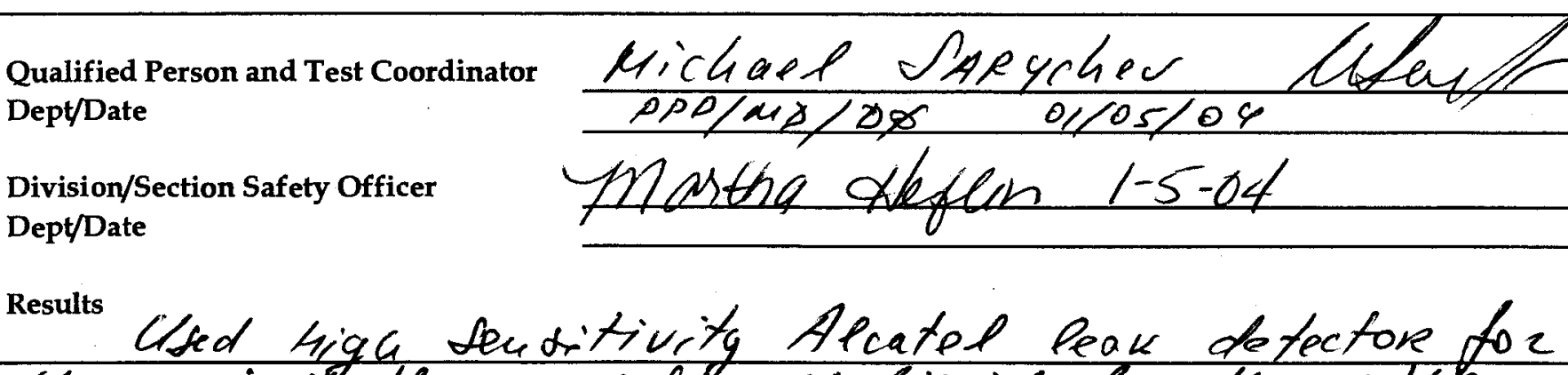
sAcrum jackets an a sap ligand for the other joints pressures gradually iucrated to $2 z$ prig.

No leaks defected. hest passed

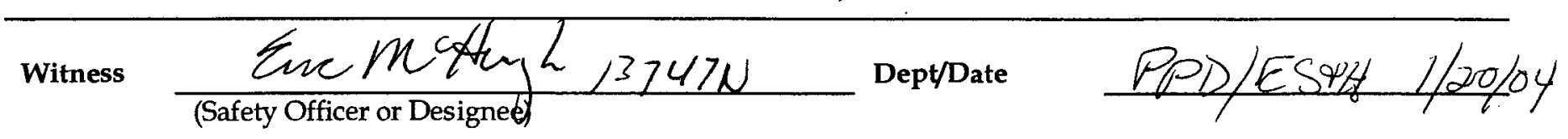

* Must be signed by division/ section safety officer prior to conducting test. It is the responsibility of the test coordinator to obtain signatures.

Fermilab ES\&H Manual

$5034 \mathrm{TA}-1$

Revised 3/2001 


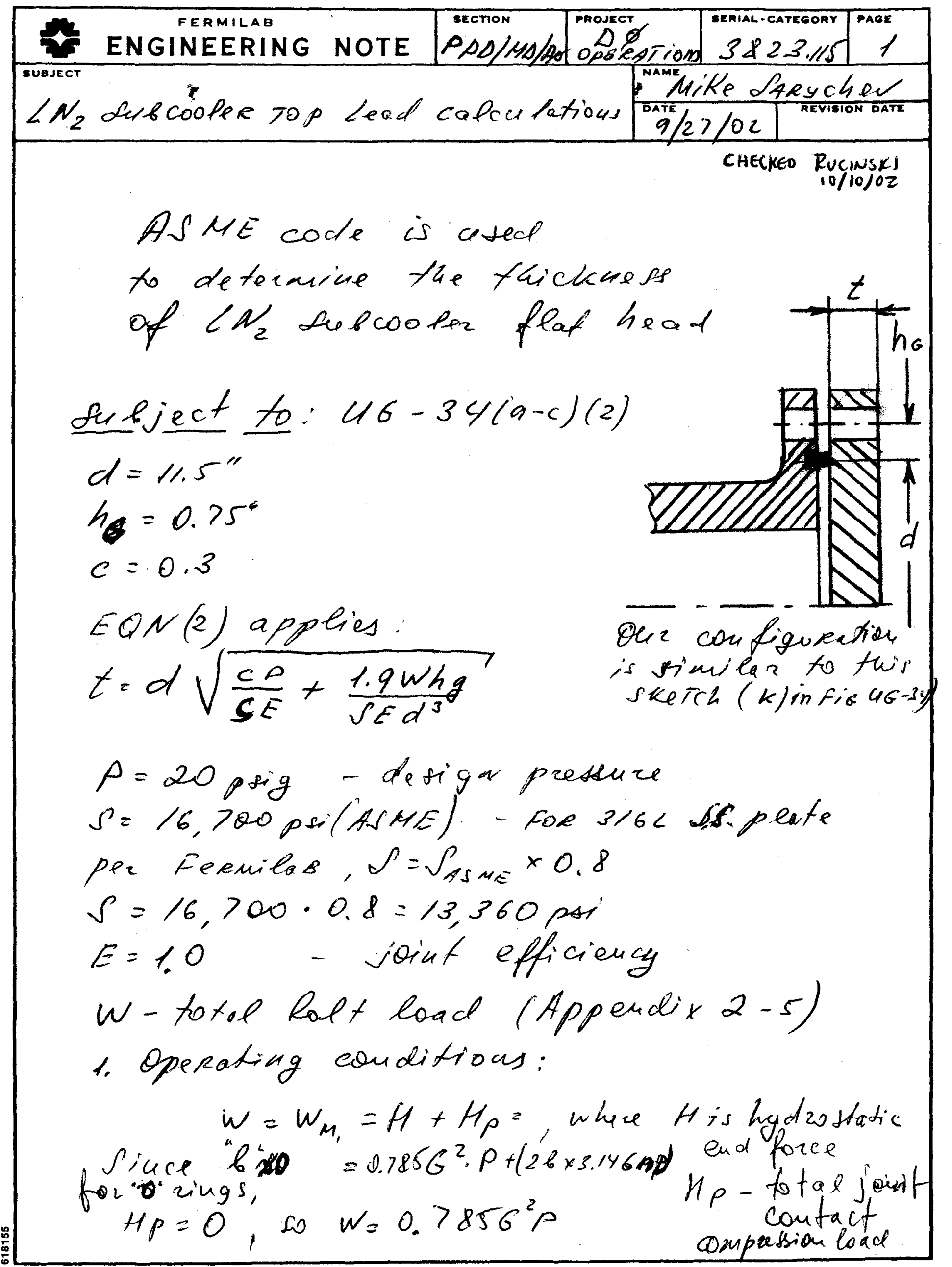




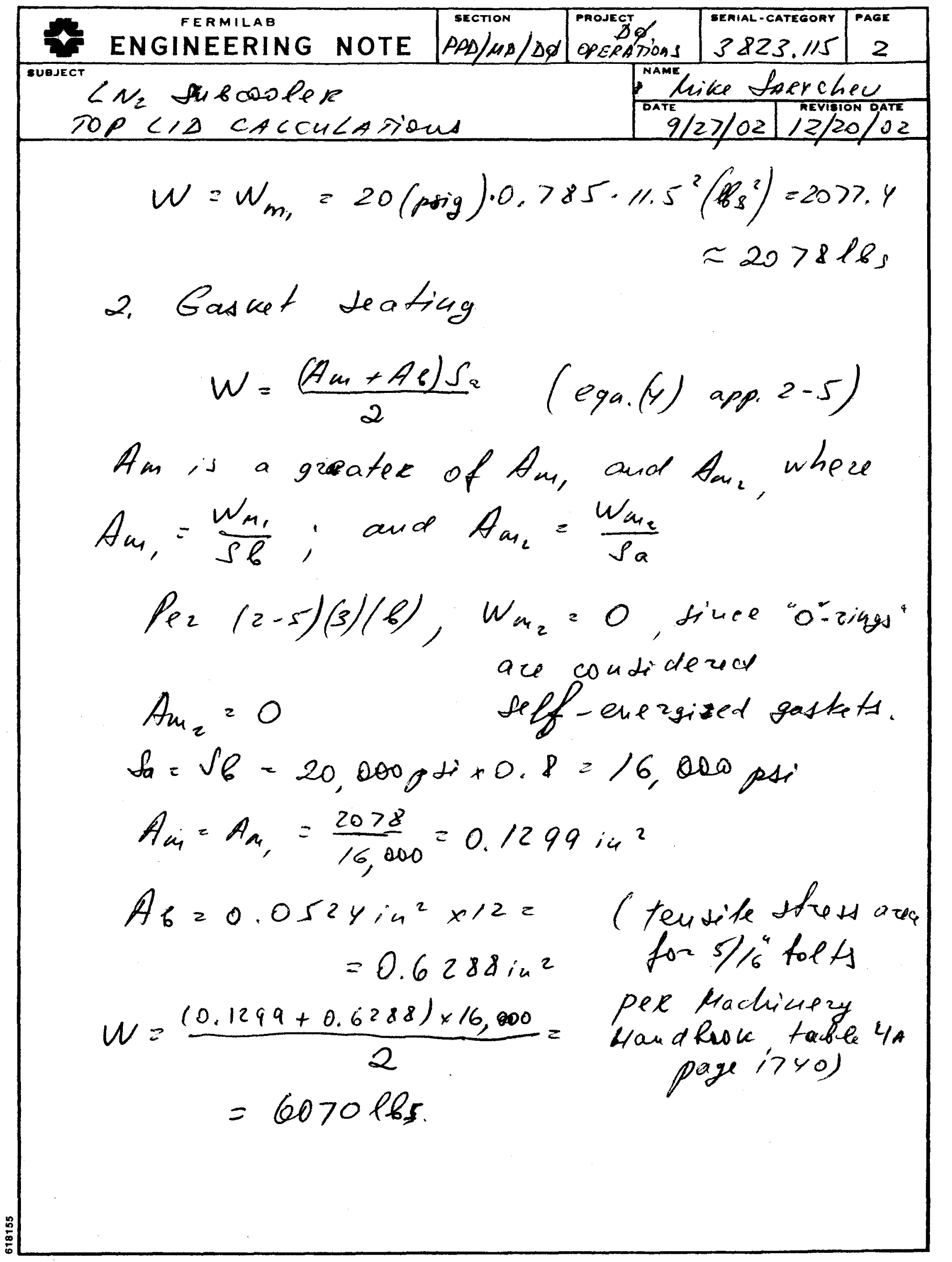




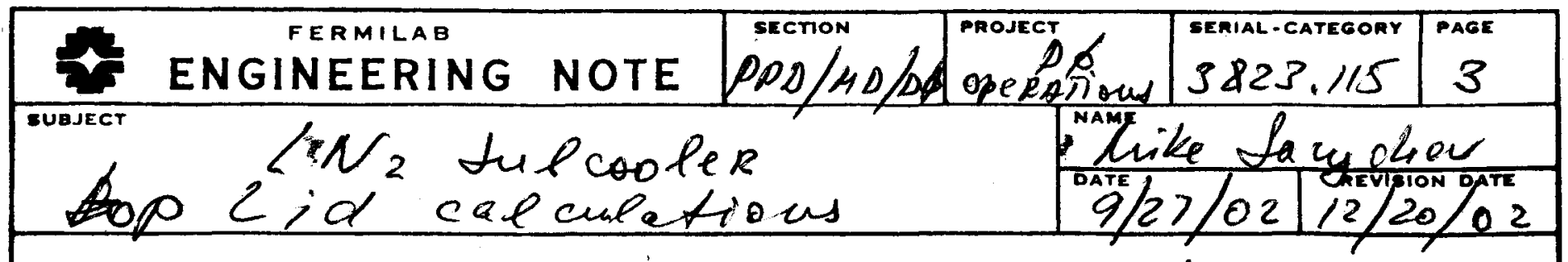

The required plate thickness for

operating conditions:

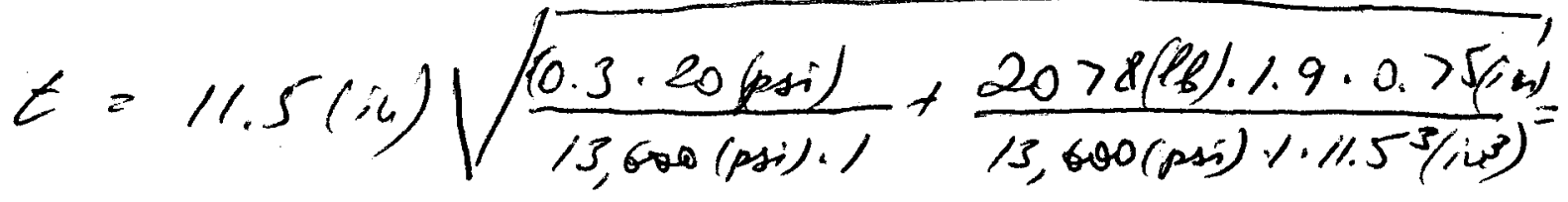

$$
\begin{aligned}
& =0.278 \mathrm{in}
\end{aligned}
$$

$$
\begin{aligned}
& \text { for gasket seating }(P=0), p_{n \in-34} \\
& t=11.5 \text { (ic) } \sqrt{\frac{6070 \cdot 1 \cdot 9 \cdot 0.75}{13,600 \cdot 1 \cdot 11.5^{3}}}=0.235 \mathrm{in}
\end{aligned}
$$

Choose the greater of $2 \Rightarrow t=0.278 \mathrm{in}$ Reinforcements (per UG-39)

Since cone of the openings exceeds one half of the head diameter ( $7^{\prime \prime}$ and no pair have an average diacreter greater then one quarter of head diameter $(3,5)$, apply ug-39(e); the dpacius between pairs is more than $I I / C$ the ave rage diameter for all pairs $(U G-39(e)(2)$, the reinforcements may be determined by rule (d), multiplied by "h". 


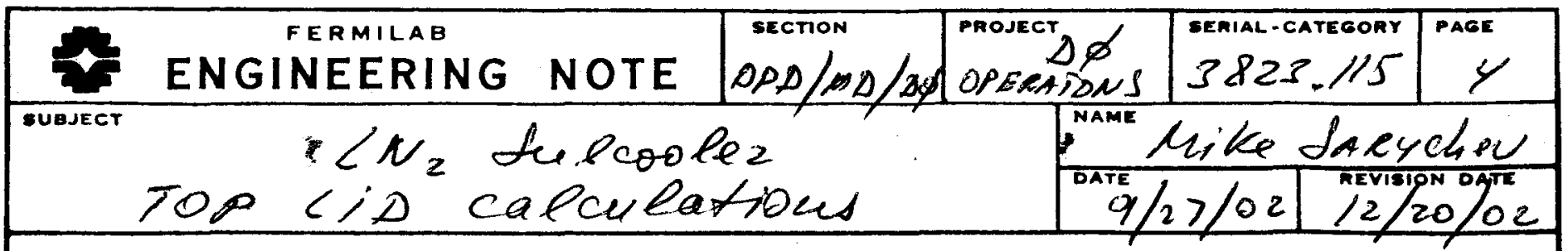

Ref. Max opening diameter is 1.900 in max. are rage pair diameter is 1,900 in (Jame diameter holes) with the Spacing of $2.956 \mathrm{in}$

Per UG-39/d)(2), the value under the square root must be doubled, and from previous rule, (U6-39(e)(r), unetiglied fy the factor of " $h$ ", where

$$
\begin{aligned}
& h=\sqrt{\frac{0.5}{e}} \\
& e=\left[\left(\rho-d_{\text {Ave }}\right) / \rho\right] \\
& e \text { - Sarallest ligament } \\
& \text { efficiency of } \\
& \text { adjacent openings } \\
& e=\frac{2.956-1.9}{2.956}=.357 \\
& \rho \text {-facing, } \rho=2.956 \mathrm{ir} \\
& h=\sqrt{\frac{0.5}{0.357}}=1.183 \\
& d_{\text {ave }}=d=1.9 \mathrm{in}
\end{aligned}
$$

the top lid thickness witt be:

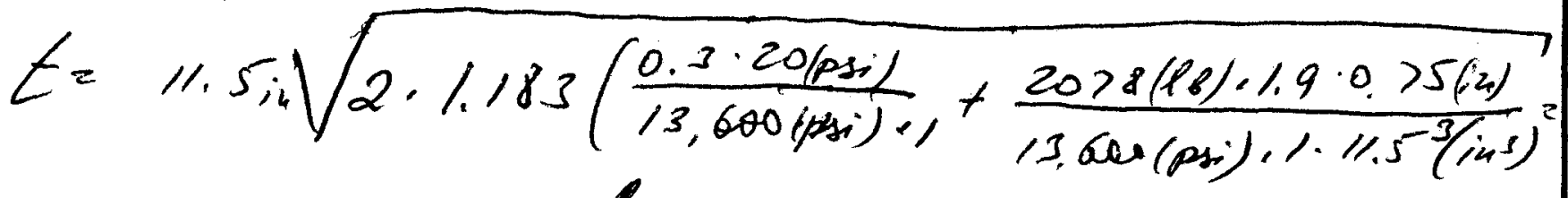

$$
\begin{aligned}
& =0.428 \mathrm{in}
\end{aligned}
$$

will choose $1 / 2$ "flick plate. 


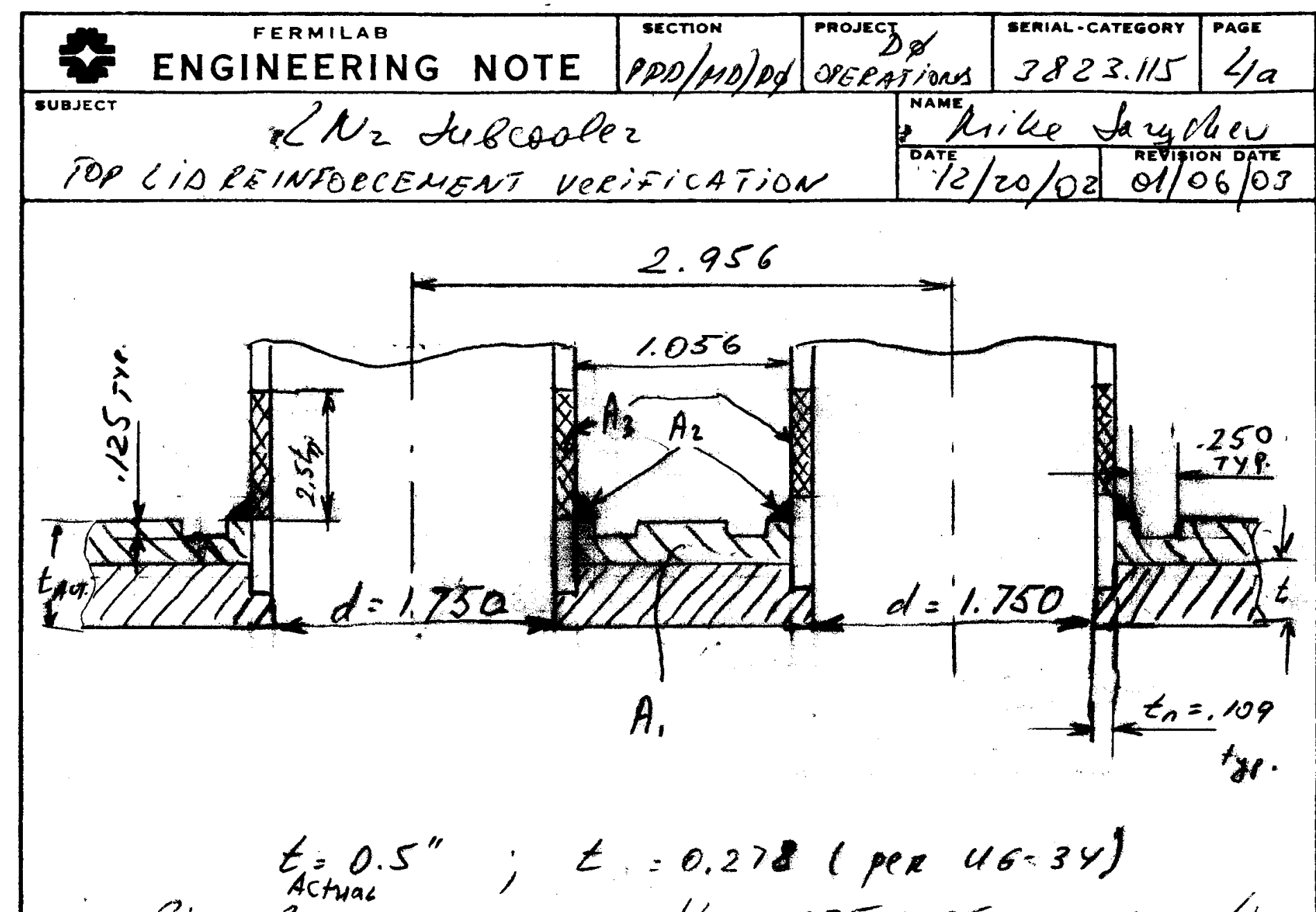

Circular grooves with .125×.250 cross section are cased to relive Stress obscuring during the welding operation. We can verify, if the material removed from the flat he id to mace this grooves will not affect the head's reinforcement.

Per $46-39(b)(2)$ for multiple openings in flat heads, the cross -sectional ara of required reinforcement for every single opening:

$$
A=0.5 d \cdot t+t t_{n}\left(1-f_{R_{1}}\right)
$$

we use the sachs curatorial for reich ore. went ( 300 series $\rho_{. S}$. ), so $S_{h}=S_{V}$, and

$$
f_{R_{1}}=\frac{s_{u}}{s_{r}}=1 \Rightarrow A=0.5 d t=0.5 \cdot 1.750 \cdot, 278=0.243
$$




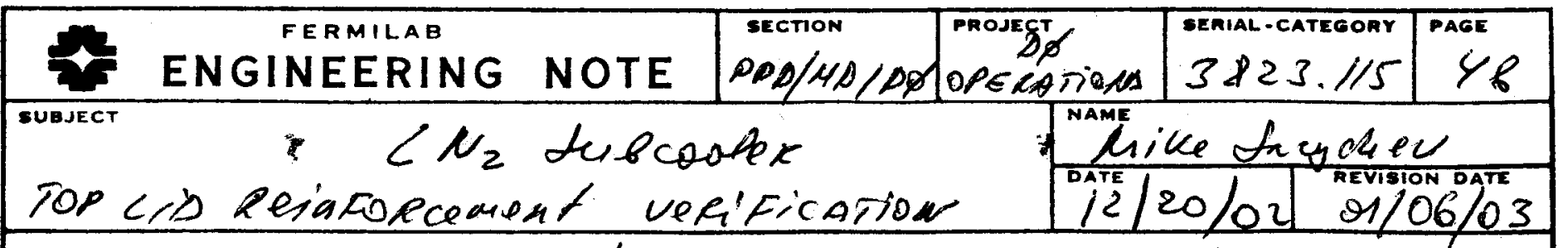
In our case, where the spacing between two adjacent openings (in the wont case) is less than twice the average diameter, fut move than $11 / 4$ of the average diameter, the reinforcement should be calculated for each hole, and 50\%, of the sum. put between these two holes. Ia on z case the openings are the lame, and the area for reinforcement is

$$
A=A_{1}+A_{2}+A_{3} \quad((A+A) \times 0.5=A)
$$

$A$, - area of increased tircuess

$A_{2}$ - 1/8" fillet weldment

$A_{3}$ - area available in nozzle, projecting ont wands.

$$
\begin{aligned}
& A_{1}=1.056 \times(0.5-0.278)-2(0.125 \cdot 0.25)= \\
& =0.172 \mathrm{in}^{2} \\
& A_{2}=0.125^{2}=0.015 \mathrm{in}^{2} \\
& A_{2}=2(109 \times 2.5 \cdot 0.109)=0.0594 \\
& \quad A=0.246 \mathrm{in}^{2}>A_{\text {required }}=0.243 \mathrm{in}^{2}
\end{aligned}
$$

Therefore, $1 / 2^{a}$ thick flat head with $1 / 4$ " $1 / 1 "$ circular grooves will be zinforred enough for 2 adjacent 1.9 of openings with :-1/2" sch. 10 pipe nozzles welded with $1 / 8$ "fillet. 


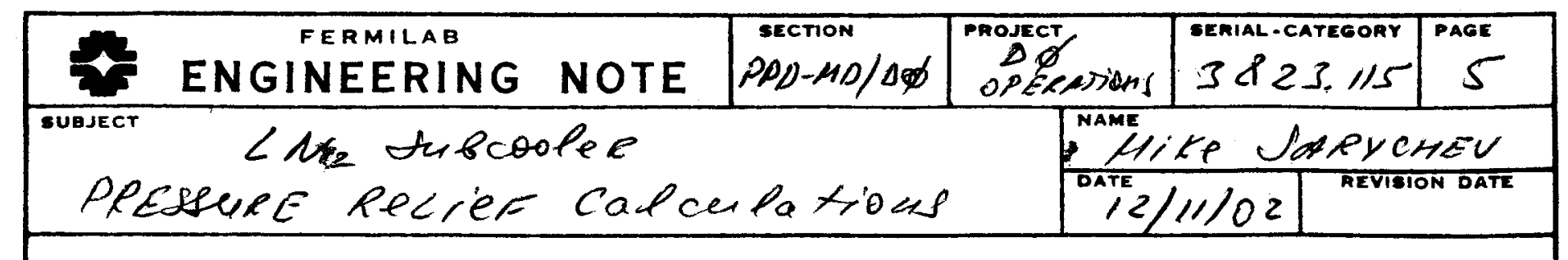

Operation emergency conditions, excleding fire (iip. vacurn loss).

peR CGA $5-1.3$, poragraph 5.2.2

$$
Q_{a}=\frac{(590-T)}{4(1660-T)} \cdot F G ; U A \text {, where }
$$

$F$-connections factore; $F=1$ (conn. pipe less than $2^{\prime}$ pere S.1.Y)

M- overacc heat temsfer coofficiont in BAu/the.ft'. of

$G_{i}$ - gas fastor - toble 1 of $\operatorname{CoA} \rho-1.3$

$$
G_{1}=10.2
$$

A - arithmetic mean area of inside and outside sunface areas of inner vestel

$$
\begin{aligned}
& D_{\text {mean }}=\frac{10.625+10.875}{2}=10.75 \mathrm{in} \\
& A=A_{\text {cyc }}+A_{\text {herisphore }} \\
& A_{\text {cyc }}=\text { F5 DH }=\text { F.c0.75.16 }=540.08 \mathrm{in}^{2} \\
& A_{\text {нем. }}=\frac{\pi}{4}\left(s^{2}+4 h^{2}\right)= \\
& =\frac{\pi}{4}\left(10.75^{2}+4.2^{2}\right)=103.27 \\
& A=540.08+.03 .27=643.35 \text { ia }^{2}=\frac{0.54}{\text { ofp }} W \\
& =4.46 \mathrm{ft}^{2}
\end{aligned}
$$




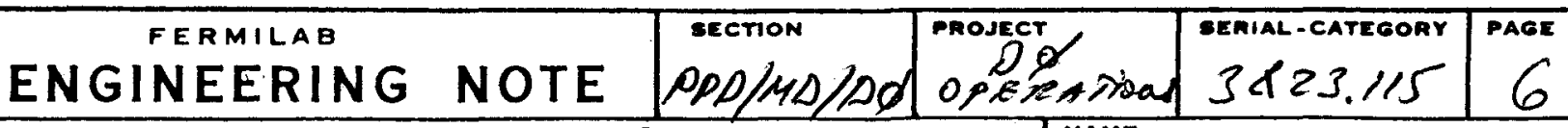
$\ll N_{2}$ dulcooler

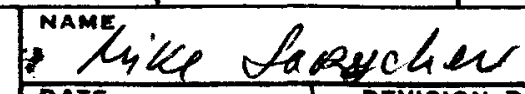

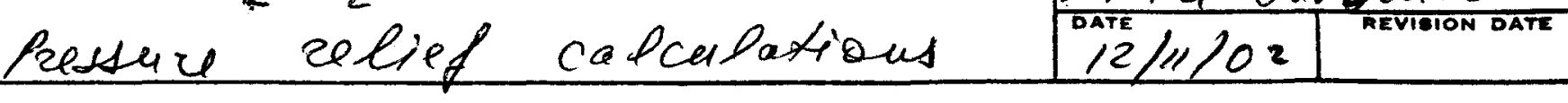
Flow rating pressure for primary system - $110 \%$ of UWAD (per CGAY.3.S.1)

Per YY.13 for vacunar indulated restels,

$$
\begin{aligned}
P=\frac{110}{100} \cdot 20 & +\frac{110}{100} \cdot 14.7-14.7=23.47 \text { prigh } \\
& =38.17 \text { psia }=2.6 \text { a Tm.als. }
\end{aligned}
$$

Tsat @2.6atm $=86^{\circ} \mathrm{K}=154.8^{\circ} \mathrm{R}$

$$
u=\frac{k}{x}
$$

$I$ would a stume 25 leyers of MYCAR + Fiber glass mesh, $\approx 3 / 8$ thick

$K$ for fiberglass (Botzon, iable 1-9, p.25)

$$
\begin{aligned}
& k=0.014 \frac{\mathrm{BgiC}}{\mathrm{HR} \cdot \mathrm{fH} \cdot \mathrm{F}}
\end{aligned}
$$

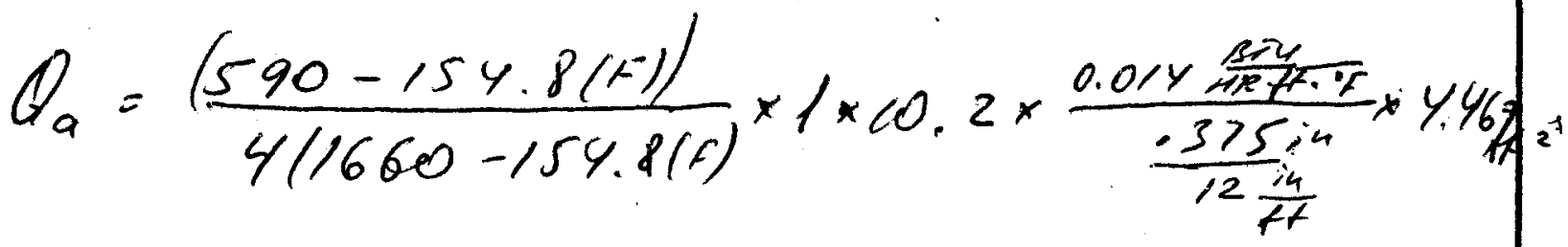

$$
\begin{aligned}
& =1.475 \mathrm{fm}
\end{aligned}
$$

Flow capreity under fine condition.

Per CGA $9-1.3$, paragraph 5.3 .3

$$
\begin{aligned}
& Q_{a}=F G_{i} C A^{0.82} \\
& F=1 ; G_{1}=00.2 \quad A=4.46 \mathrm{ft}^{2}
\end{aligned}
$$




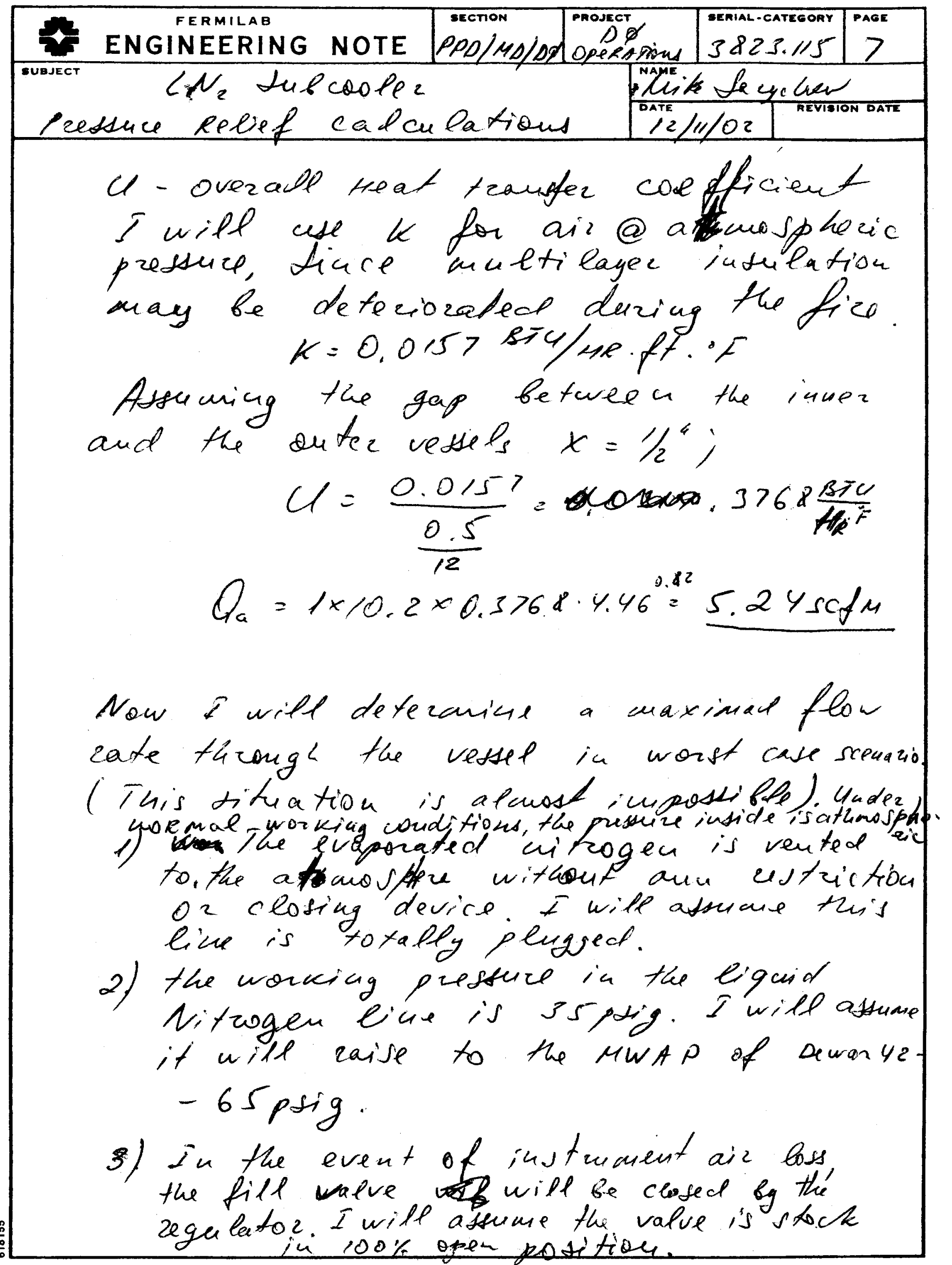




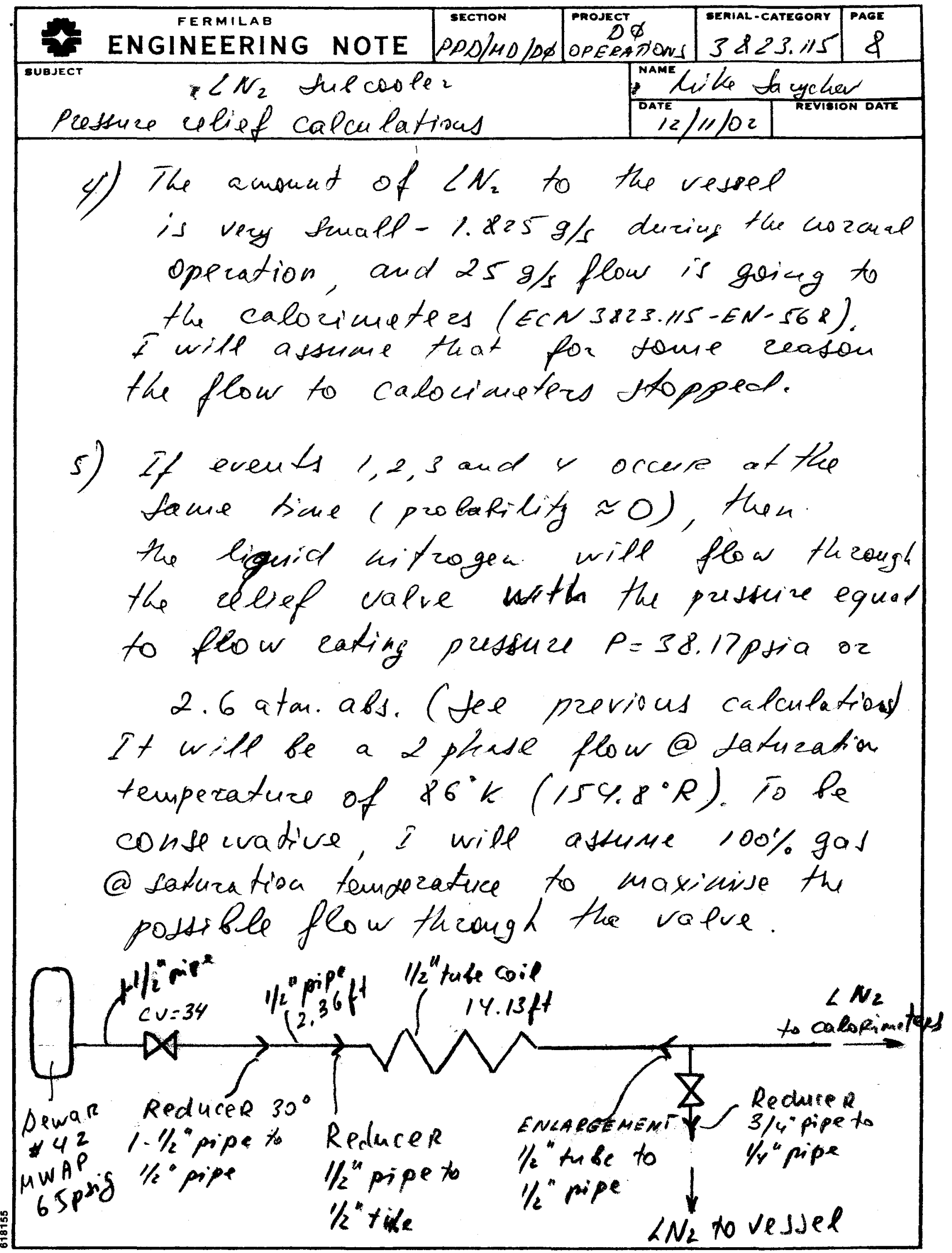




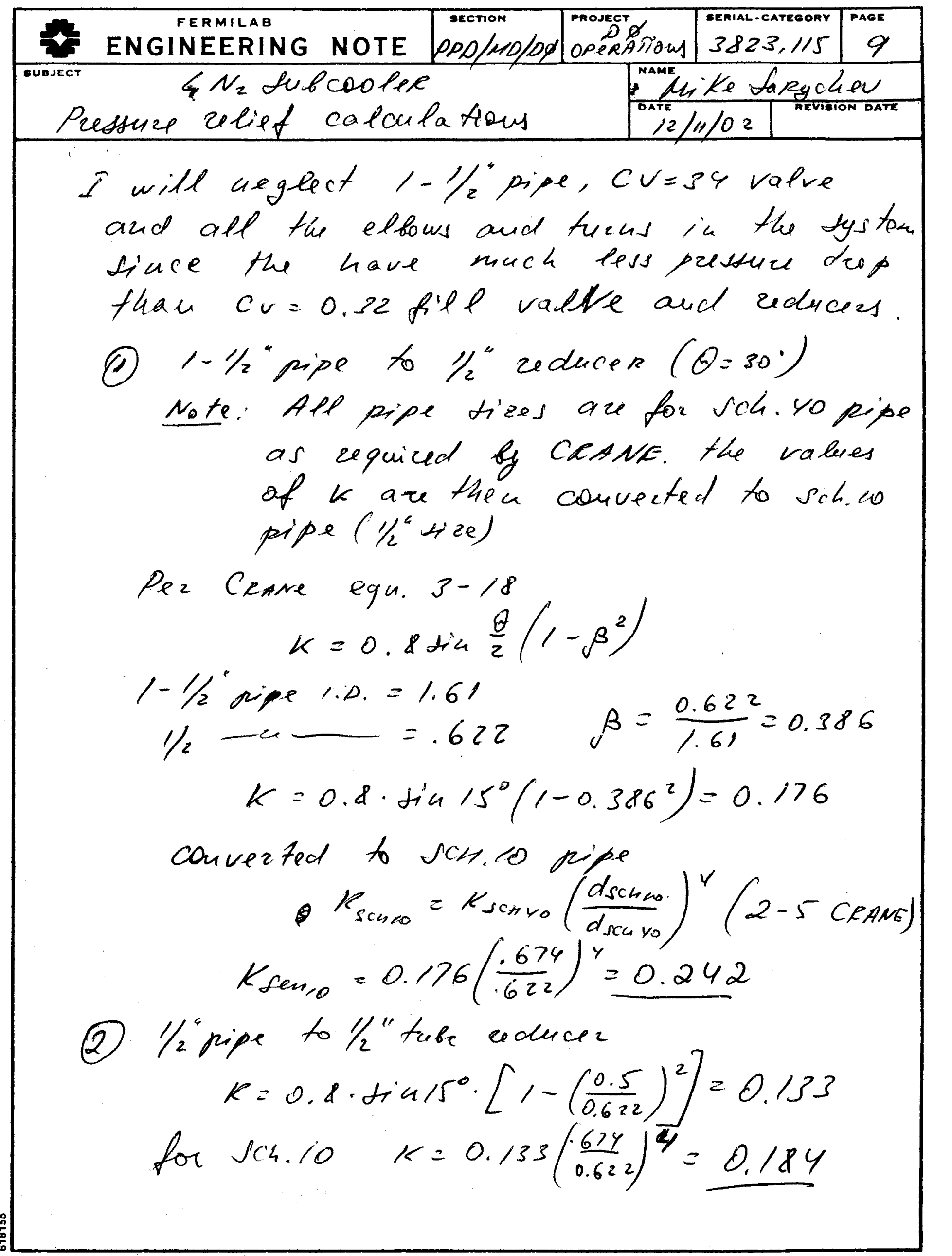




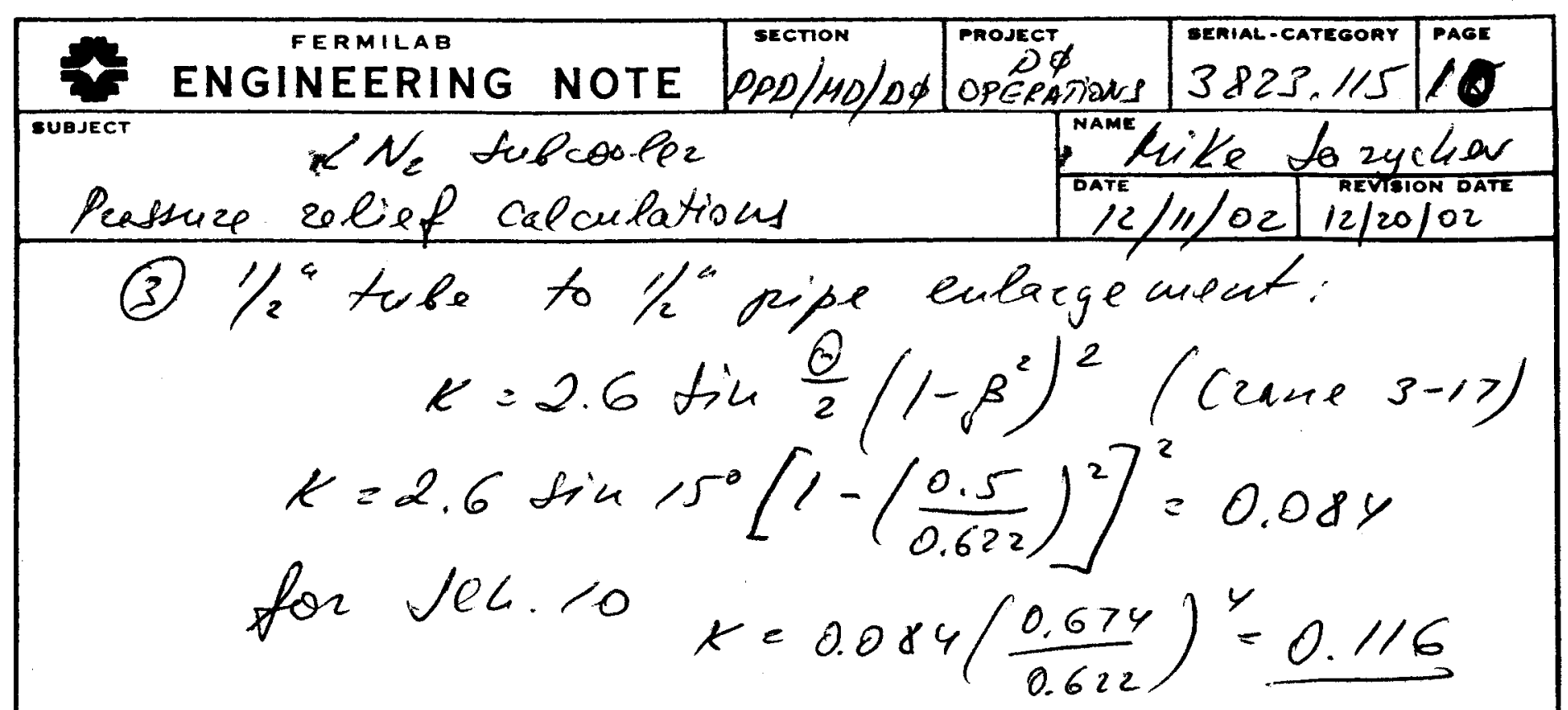

(4) Value, $c_{v}=0.32,1 / 2^{*}$ pipe

$$
\begin{gathered}
k=\frac{891 \cdot d^{2}}{C v^{2}} \quad(\text { crane } 3-16) \\
k=\frac{891 \cdot 0.62^{2}}{0.32^{2}}=1302.38(! \text {-determines } \\
\text { the flow) }
\end{gathered}
$$

for rel. 10

$$
x=1302.38\left(\frac{.674}{.622}\right)^{y}=1795.6
$$

(5) 3/4 pipe elbow to $1 / 4$ pipe reducer (before the

$$
\begin{aligned}
& K=0.5 \sqrt{\sin \frac{\theta}{2}} \cdot\left(1-\beta^{2}\right)\left(\theta 2180^{\circ}\right) \text { phase }{ }_{\text {senator) }} \\
& \text { (crane 3-18.1) } \\
& k=0.5 \sqrt{\sin 90}\left[1-\left(\frac{400}{804}\right)^{2}\right]=0.392
\end{aligned}
$$

for sch. co $K=0.38\left(\frac{6.674}{0.622}\right)^{4}=0.541$

$$
E K=.242+.184+.116+1795.6+.54 \%=1796.7
$$

Equivalent length

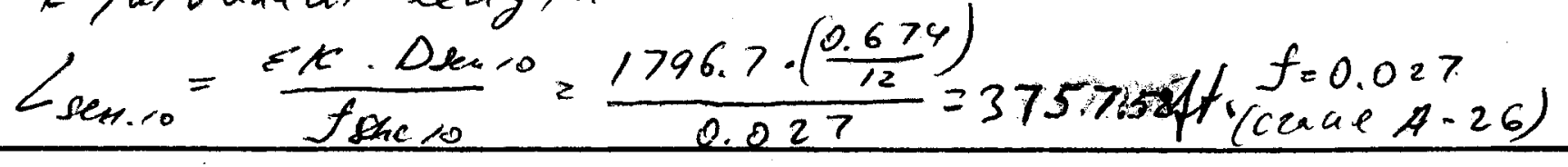




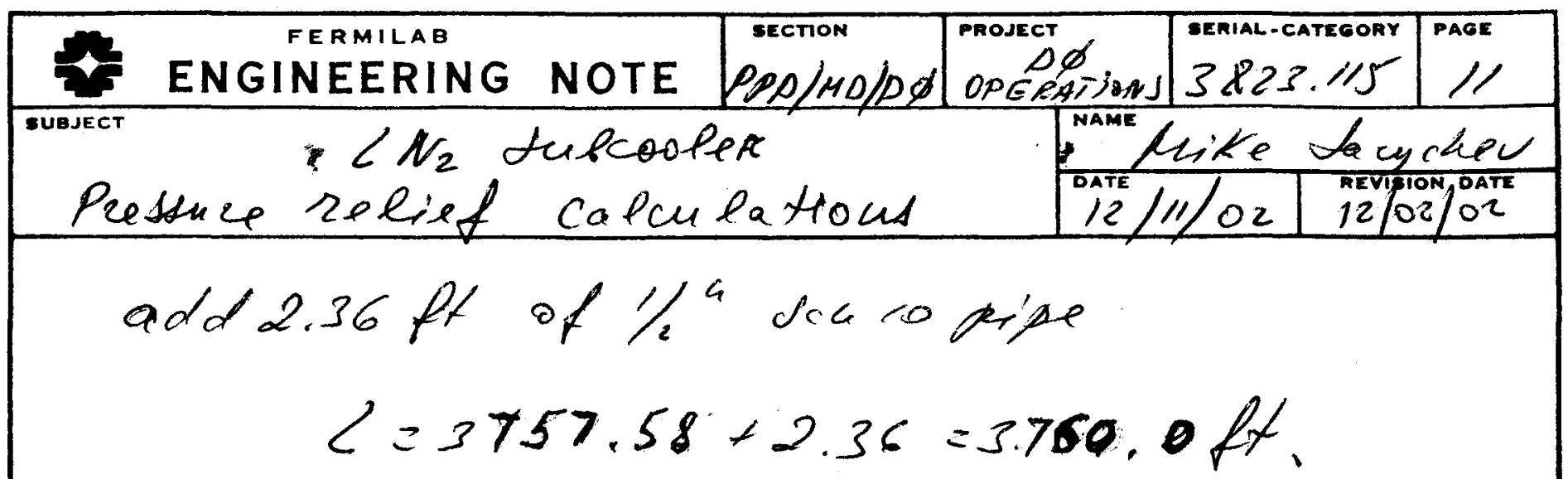

Rearanged Daxcy's formule:

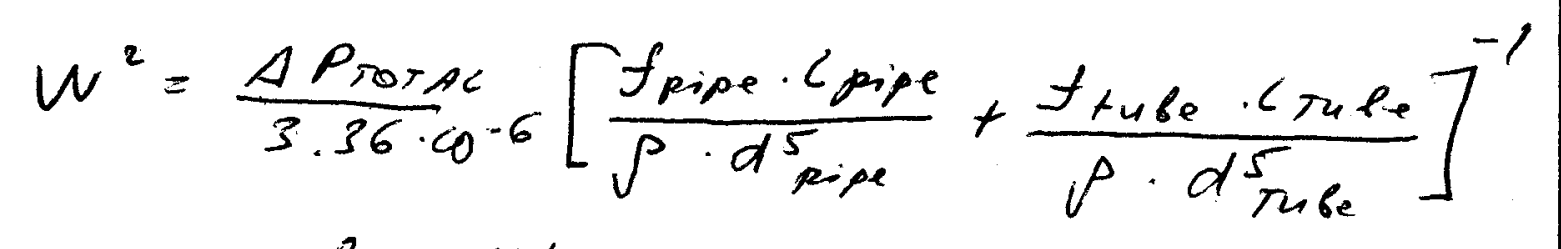

$f=0.027$ for $1 / 2$ pipe

I will use $f=0.026$ for $1 \%$ " wopper tubp ( see eng. wote 3823.115-EN-568)

$$
\begin{aligned}
& W=\sqrt{\frac{(65-23.5)}{3.36 \cdot 60^{-6}}\left[\frac{0.027 \cdot 3760.0}{477 \cdot 0.674^{5}}+\frac{0.026 \cdot 14.13^{7}}{477 \cdot 0.5^{5}}\right]^{\prime}}= \\
& =891 \mathrm{lb} / \mathrm{yr} \\
& \rho=76.42 \cdot 0^{-2} \mathrm{~g} / \mathrm{ar}_{3}=47.7 \mathrm{lo} / \mathrm{ft} \text { for } p=23.5 \mathrm{psi} \mathrm{g} \\
& T=86 \mathrm{k} \text { for } \\
& \text { Saluzated eiquid) }
\end{aligned}
$$

Check friction factors:

$$
\begin{aligned}
& R_{e}=6.31 \frac{\mathrm{W}}{d \cdot \mu} \quad R_{\text {pipe }}=6.31 \frac{891}{.674 \cdot 0.1104}=7.6 \cdot 10^{4} \\
& \mu=0.1104 \mathrm{cp} \quad R_{e} A_{4} b_{e}=6.31 \frac{.891}{.5 \cdot 0.1104}=10.2 .00^{4} \\
& \text { 11) } \\
& f_{\text {mipe }}=0.02 ; f_{\text {tn }}=0.0285 \\
& \text { (cracue A-25) }
\end{aligned}
$$




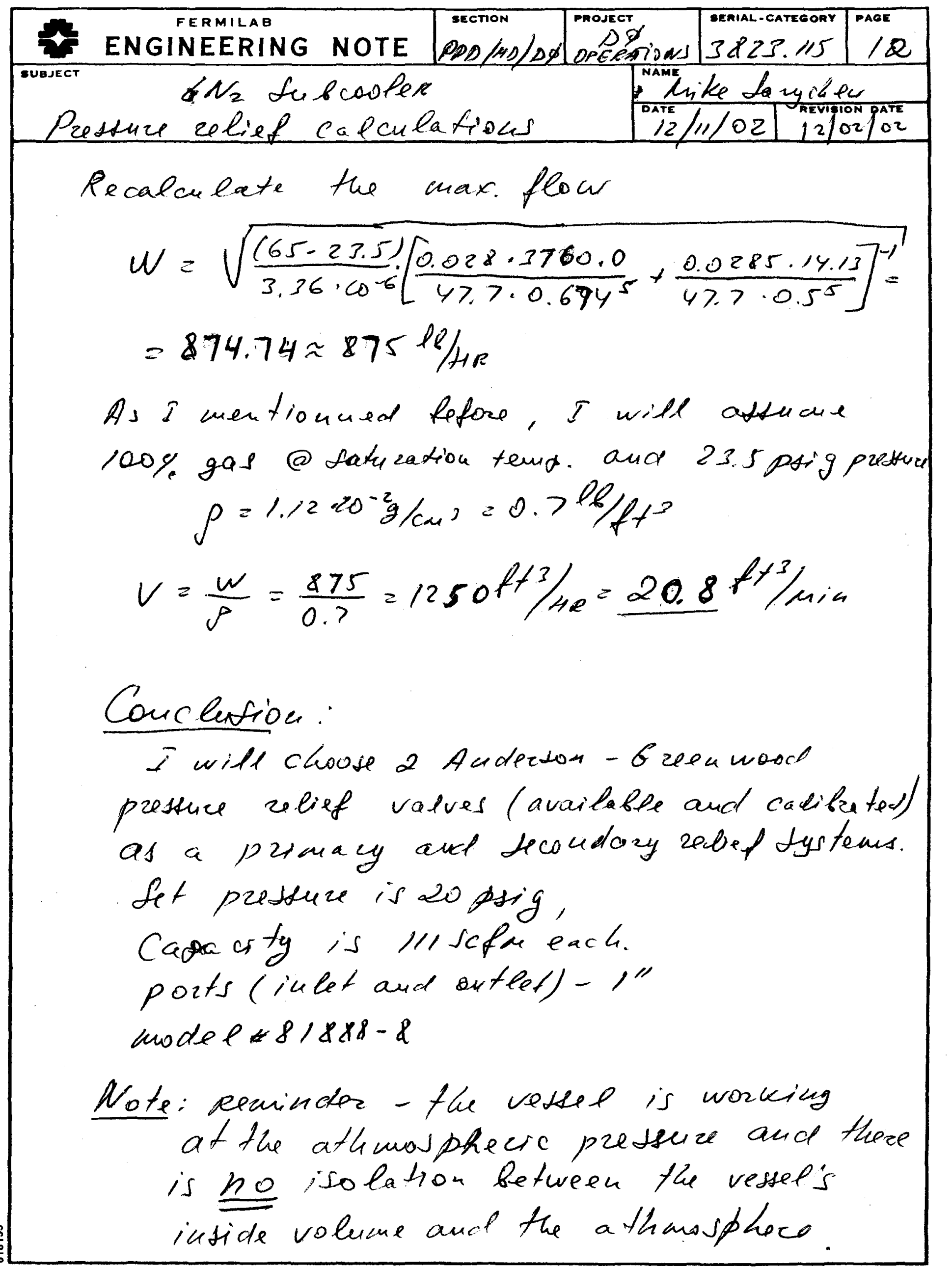




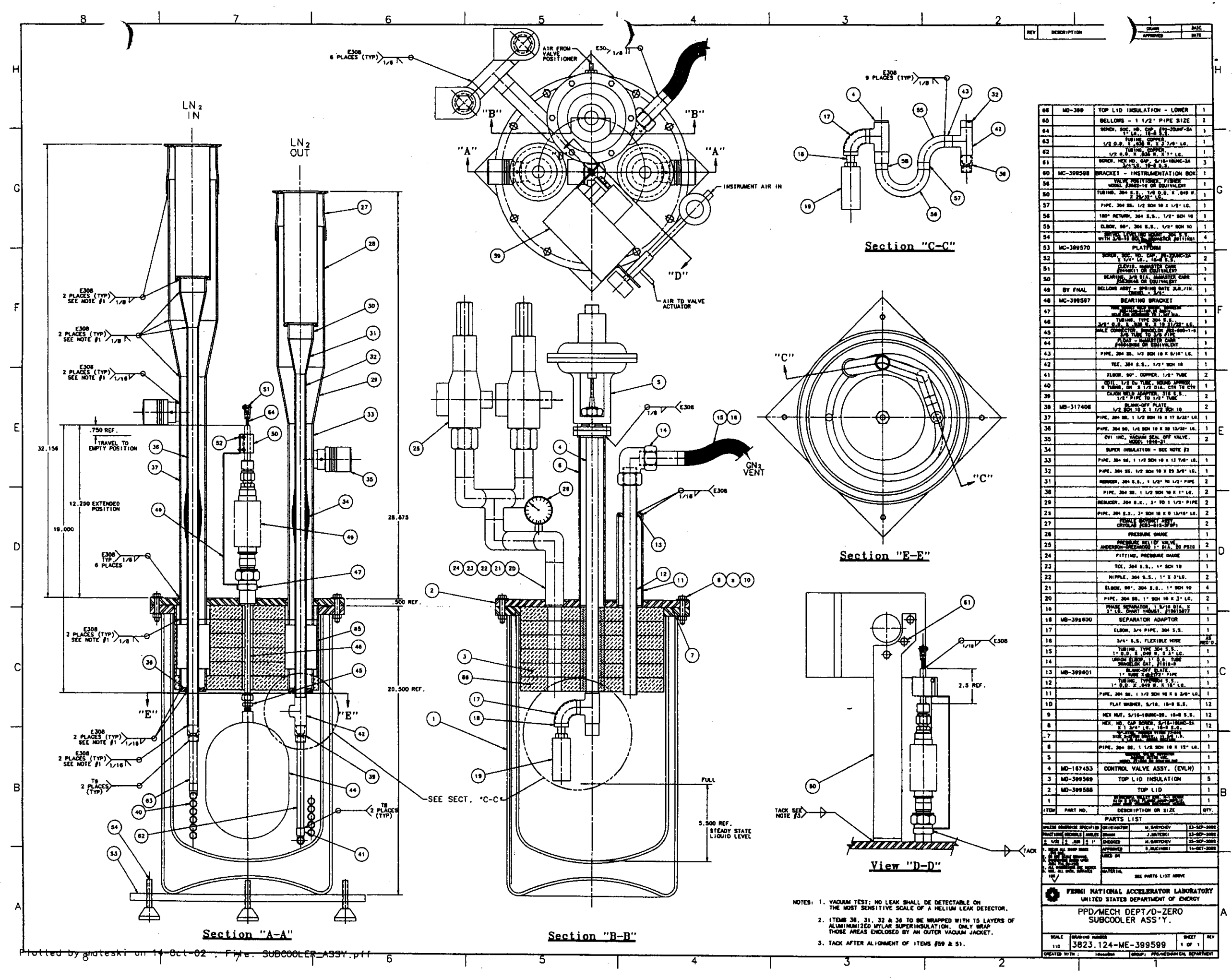




\section{VALVE REPAIR WORK ORDER}

PRESSURE MANAGEMENT CENTER

Elk Grove Village, IL 60007

$847-952-6210$

Page of $\quad$ VSCR

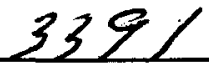

Customer

\section{Eevilab}

Location

RECORD OF ORIGINAL NAMEPLATE DATA

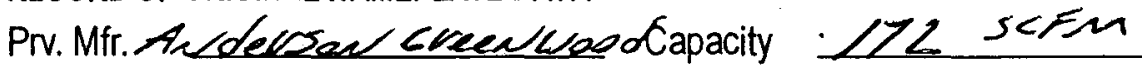
PO\#

Date Rec'd $9-\angle 6-02$

Type No. $8 / 1888 \&$

Inlet/Outlet $\angle$ in. $/ \angle$ in.

ASME Code Stamp CU

Set Press

PSIG Tag No.

Mfr. SINZ58Z5Y

CHANGE IN SET PRESSURE:

\section{RECORD OF PRETEST (AS FOUND)}

Test Pressure

Blowdown

Tightness

Action

4

Reset To ZO PSIG

New Capacity

Trim No.

RECORD OF PREVIOUS REPAIR

Pretest Sign-Off

Tested by

Date

M\&TE S/N
By

Model

Capacity

Unique \#
Set

Date

VR Stamp
RECORD OF DISASSEMBLY \& CLEANING

Item (s): "As Found Conditions"

Cap and Lever

Bonnet/Compr Scr: . 980

Spring/Steps

Spindle/Disc

Rase/Nozzle

-uide/Adj. Rings

Other (Specify)

\begin{tabular}{|c|c|c|c|}
\hline \multicolumn{4}{|c|}{ RECORD OF CRITICAL INSPECTION \& MACHINING } \\
\hline Comments & OK & Machine & Replace \\
\hline 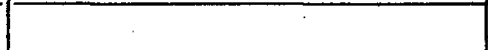 & $\bar{x}$ & & \\
\hline & X & & \\
\hline Springlye \& B P p/K Bls & & & $x$ \\
\hline T.I.R. & & & $x$ \\
\hline Bore Dia. . $5 \overline{0}$ & & $\angle A D$ & \\
\hline & $x$ & & \\
\hline & & & \\
\hline
\end{tabular}

\begin{tabular}{|c|c|c|}
\hline \multicolumn{3}{|c|}{ RECORD OF REPLACEMENT PARTS } \\
\hline Part No & Description & PO\# \\
\hline of 1805003 & seperes & Kustaper suppyed \\
\hline $04-4805-005$ & saft Goods KIT & Eustameir supped \\
\hline & & \\
\hline & & \\
\hline Notes & & \\
\hline
\end{tabular}

RECORD OF TECHNICIAN SIGN-OFF

Repair Step

Nameplate

Disassembly

Cleaning

Inspection

Machining

Machining

- Assembly

Testing Initials Date 75 75 $5-16-a$ 25 2-16-02

\section{RECORD OF FINALTEST RESULTS}

Test Stand/Media LBlooan BLV

Final-Assembly $\geq 2$ \& $24-02$

VR Stamp $\Phi N$ 互 $Q-24-0 L$

\section{Repaired by}

GM\&C VALVE SERVICE COMPANY Elk Grove Village, IL VA No. 396 \& 500 VSCA. 3382 DATE 8.02

( STYLE $8 / 388-8$ SET PRESS $Z 0$ CAP II SCE 


\section{TEST DOCUMENTATION \\ CODE STAMPED RELIEF VALVES}

This form should be used for relief valves returned from a vendor to check the accuracy and quality of the vendor's work. It should also be used to check code stamped valves for the 6 year test. Valves that pass this test can be put in service if the original seal from a vendor is still in place and not broken.

All valves should be bubble tight at $90 \%$ of set pressure while increasing pressure, lift within the code requirement, and reset bubble tight. Reset pressure as a percent of set pressure would vary, depending on the blowdown setting.

The valve should be connected to the appropriate test chamber with adapters as required being careful not to choke the valve with fittings smaller than the valve inlet.

Date- October 1,2002

Vessel number (from silver sticker) -

Physical location and valve number -

Manufacturer - Awderson Greenwood

Model number - $81388-8$

Serial number - 158254

Valve size - $1^{n}$

Seal intact - yes.

Set pressure - 20 psis

Bubble tight at 90\% set pressure-@18psig-Slight reakage-OK@16.0 psig $=80 \mathrm{Z}_{0}$

Valve lift within $+/-2$ psig for settings 70 psig and below or within $3 \%$ for higher settings? Tolerances defined by UG- 134(d) (1) OK

Test 1 - $20.3 p x^{i}$ Test $2-20.3 p$ si Test $320.3 p$ si

Bubble tight at reset - @1 3.0 si.

If valve passed test, attach a brass tag to valve with "TEST ONLY", date, and tester's initials.

Notes; Performance test of Vendor's (Jertification

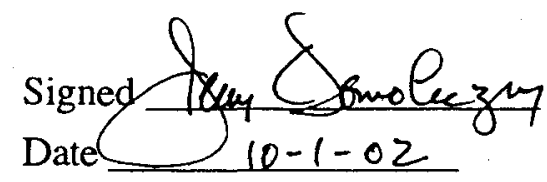


847-952-6210

Page _ $\angle$ of $\quad$ VSCR-

Customer Lenelah

PO\# POCARd

Location

RECORD OF ORIGINAL NAMEPLATE DATA

Prv. Mfr. Redecsectireectereod Capacity Date Rec'd $8-20-02$

Type No. $8 / 288-8$

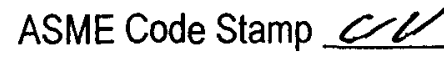
InletOutlet in. $/ \angle$ in. Mfr. S/NZ 28258 CHANGE IN SET PRESSURE:

Set Press PSIG Tag No.

RECORD OF PRETEST (AS FOUND)

Test Pressure

Blowdown

Tightness

Action
Trim No.

Pretest Sign-Off Tested by Date M\&TE S/N
RECORD OF PREVIOUS REPAIR

By

Model Capacity Unique \# New Capacity 20 3389

RECORD OF DISASSEMBLY \& CLEANING

Item (s): "As Found Conditions"

Cap and Lever

Bonnet/Compr Scr: . 978

Spring/Steps

Spindle/Disc

Rase/Nozzle

uide/Adj. Rings $\leq 5$

Other (Specify)

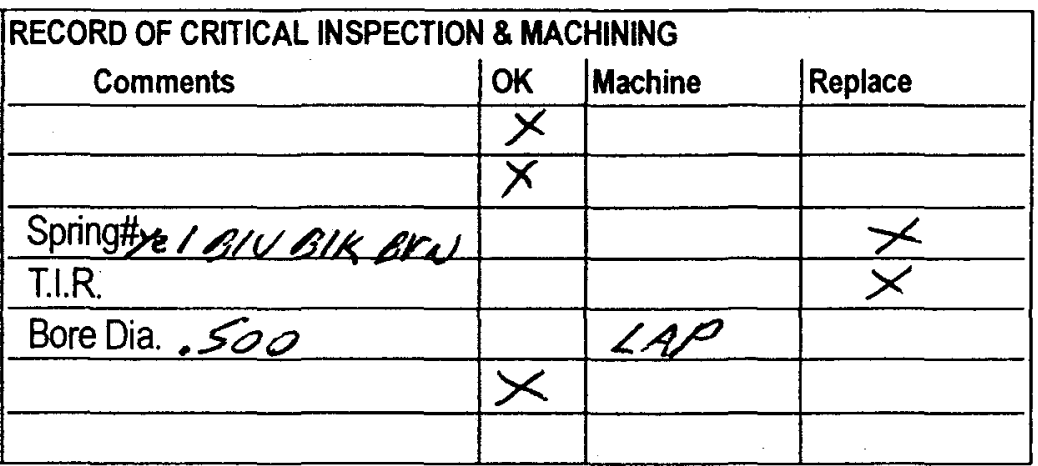

\begin{tabular}{|c|c|c|}
\hline \multicolumn{3}{|c|}{ RECORD OF REPLACEMENT PARTS } \\
\hline Part No & Description & PO\# \\
\hline $04-4805-005$ & 81 seft Goods $/ \mathrm{KT}$ & Custemeir suppyed \\
\hline & SPMVY PINK BIK BIK BWW & Customer sugosed \\
\hline & & \\
\hline & & \\
\hline
\end{tabular}

Notes RuBBeW WAS STUCK le lallet

RECORD OF TECHNICIAN SIGN-OFF

Repair Step Initials

Date

RECORD OF FINAL TEST RESULTS

Nameplate $-25 \quad 82002$ Test Pressure $\angle 0$

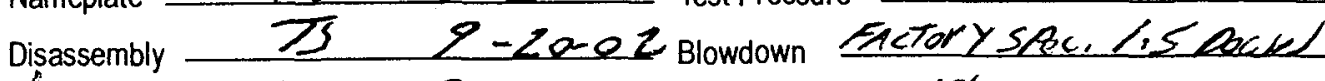

Cleaning $15 \quad 2-20-02$ Tightness 18

Inspection $\frac{75}{3}-20-02$ M\&TE SIN 16600

Machining

$$
73
$$$$
\text { 9-20-02 }
$$

MSsembly

Testing

75

$7-23-a z$

Final-Assembly DF 924.02

VR Stamp $\theta N$ TE \& L 2402

\section{Repaired by}

GM\&C VALVE SERVICE COMPANY Elk Grove Village, IL VA No. $396 \& 500$ VSCR 3382 DATE $\$-02$

$\oplus$ STYLE $81088-8$ SET PRESS $Z 0$ CAP LN SCFA 


\section{TEST DOCUMENTATION CODE STAMPED RELIEF VALVES}

This form should be used for relief valves returned from a vendor to check the accuracy and quality of the vendor's work. It should also be used to check code stamped valves for the 6 year test. Valves that pass this test can be put in service if the original seal from a vendor is still in place and not broken.

All valves should be bubble tight at $90 \%$ of set pressure while increasing pressure, lift within the code requirement, and reset bubble tight. Reset pressure as a percent of set pressure would vary, depending on the blowdown setting.

The valve should be connected to the appropriate test chamber with adapters as required being careful not to choke the valve with fittings smaller than the valve inlet.

Date - Oetober 1,2002

Vessel number (from silver sticker) -

Physical location and valve number -

Manufacturer-Anderson Greenwood

Model number - $81388-8$

Serial number - 758258

Valve size -

Seal intact - yes

Set pressure - 20 psig

Bubble tight at $90 \%$ set pressure-0K@16.5psig_@82.5\%

Valve lift within $+/-2$ psig for settings 70 psig and below or within $3 \%$ for higher settings? Tolerances defined by UG-134(d) (1) OK

Test 1 - 19.5 psi Test $2-19.6$ psi Test 319.5 psi

Bubble tight at reset-@16.5 psig

If valve passed test, attach a brass tag to valve with "TEST ONLY", date, and tester's initials.

Notes; Performance test of Vensor's Pertification

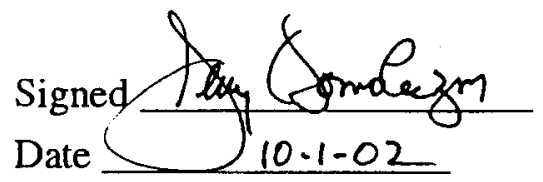


$+$

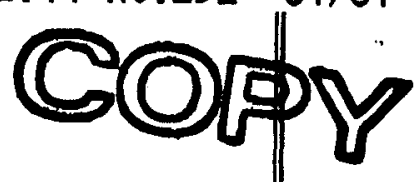

Welder's Name_Leonard Harbecek_Ident No. 122261 Date $03 / 19 / 99$

Welding Process GTAW Type Manual

Test in Accordance With WPS \# ES-155003 Root

Open

Material Specification SA 53-B To Material Specification_SA 53-B

P-No 1 To P-No 1 Thickness $280^{\prime \prime}$ Diam 6"

Filler Metal Specification SFA A5.18 Classification ER-70S-2 F-No 6 Thickness Deposited .280

Backing Argon Gas Shielding Argon

Position 6-G Progression Upward

Electrical Characteristics:

Current DC Polarity Straight Thickness Qualified 560" Max Diameter Qualified 2-7/8" O.D. and over GUIDED BEND TEST RESULTS

\begin{tabular}{llll} 
Specimen No & Type & Figure & Results \\
\hline 1 & Face & QW-462.3a & Acceptable \\
2 & Face & QW-462.3a & Acceptable \\
3 & Root & QW-462.3a & Accoptable \\
4 & Root & QW-462.3a & Accoptable
\end{tabular}

Test Conducted By_IFR Engineering Test No._008-09-01 Date 3/19/99

We certify that the statements in this record are correct and that the test weld were prepared, wolded and tested in accordance with the requirements of Section IX of the ASME Code.

By:

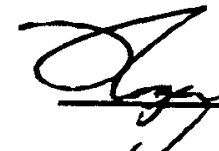

Date:

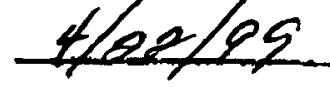


January 30,2004

To: John Cooper

From: Kurt Krempetz

Subject: $\quad$ Recommendation to Approve Pressure Vessel \# 10075-LN2 Subcooler

John,

I have looked into unusual features with Engineering Pressure Vessel Note for vessel \#10075-LN2 Subcooler and have no concerns. This note does follow the Fermilab Pressure Vessel Standard Chapter 5031 and I recommend that you sign off on the Engineering Note. 